\title{
Analisis Kesesuaian Lahan Sumber Daya Perkebunan Untuk Komoditas Prospektif di Provinsi Jawa Barat
}

\author{
RADEA ADLIN PRIMAWAN, INDRIANAWATI
}

\author{
Jurusan Teknik Geodesi \\ FTSP - Institut Teknologi Nasional, Bandung \\ Email: radeaadlinprimawan@gmail.com
}

\begin{abstract}
ABSTRAK
Provinsi Jawa Barat memiliki tiga komoditas perkebunan, yaitu komoditas strategis, prospektif, dan unggulan spesifik lokal. Untuk mengoptimalkan potensi sumber daya perkebunan, diperlukan analisis kesesuaian lahan agar dapat diketahui tingkat kesesuaian lahan komoditas perkebunan tertentu. Penelitian ini bertujuan untuk menganalisis dan mengevaluasi sebaran wilayah yang dapat dijadikan sebagai lahan sumber daya perkebunan untuk komoditas prospektif di Provinsi Jawa Barat. Metode yang digunakan adalah metode scoring. Data yang digunakan sebagai parameter kesesuaian lahan, meliputi temperatur, curah hujan, lereng, drainase tanah, tekstur tanah, dan jenis tanah. Hasil penelitian menunjukkan terdapat 5 tanaman dari 12 jenis tanaman sumber daya perkebunan komoditas prospektif yang masih dapat rekomendasikan lahannya, meliputi kemiri sunan $(40.617,75$ ha) yang tersebar di 10 kabupaten/kota, lada (2.828,71 ha) yang tersebar di 4 kabupaten/kota, kayu manis (177,36 ha) yang tersebar di 4 kabupaten/kota, kemiri $(40.617,75$ ha) yang tersebar di 10 kabupaten/kota, dan panili $(674,21$ ha) yang tersebar di 5 kabupaten/kota. Luas lahan perkebunan yang direkomendasikan tersebut secara kualitatif diketahui mengalami penurunan setelah dilakukan validasi terhadap tutupan lahan terbaru (interpretasi citra dengan google earth).
\end{abstract}

Kata kunci: perkebunan, komoditas prospektif, Provinsi Jawa Barat

\begin{abstract}
West Java Province has three commodities, those are strategic commodities, prospective commodities, and superior local specific commodities. To optimize the potential of plantation resources, the analysis of the potential of land suitability is required in order to know the level of land suitability of certain plantation commodities. This research intends to analyze and evaluate the area that can served as land resources for prospective commodities plantation in West Java Province with a scoring method. The data used as land suitability parameters are temperature, rainfall, slope, soil drainage, soil texture, and soil type. The results showed that there are 5 plants from 12 types of plantation resources of prospective commodities that the land could still be recommended, which are sunan candlenut (40617.75 ha) scattered in 10 regency/city, pepper (2828.71 ha) scattered in 4 regency/city, cinnamon (177.36 ha) scattered in 4 regency/city, candlenut (40617.75 ha) scattered in 10 regency/city, and vanilla scattered in 5 regency/city. The recommended plantation area decreased qualitatively after validation of the latest land cover (image interpretation with google earth).
\end{abstract}

Keywords: plantation, prospective commodities, West Java Province 


\section{PENDAHULUAN}

Jawa Barat merupakan salah satu provinsi di Indonesia mempunyai luas wilayah $37.173,97$ $\mathrm{km}^{2}$. Provinsi Jawa Barat terdiri dari 27 kabupaten/kota, meliputi 18 kabupaten dan 9 kota, dengan jumlah kecamatan sebanyak 627 kecamatan dan memiliki 5.962 desa/kelurahan. Provinsi Jawa Barat memiliki perkebunan yang dikelola oleh perkebunan besar milik negara dan swasta serta perkebunan rakyat. Komoditi potensialnya adalah teh, kelapa, kelapa sawit, tebu, dan karet (BPS Provinsi Jawa Barat, 2017).

Menurut Undang-Undang Republik Indonesia Nomor 18 Tahun 2004 tentang Perkebunan, disebutkan bahwa perkebunan adalah segala kegiatan yang mengusahakan tanaman tertentu pada tanah dan/atau media tumbuh lainnya dalam ekosistem yang sesuai, mengolah dan memasarkan barang dan jasa hasil tanaman tersebut, dengan bantuan ilmu pengetahuan dan teknologi, permodalan serta manajemen untuk mewujudkan kesejahteraan bagi pelaku usaha perkebunan dan masyarakat. Jenis komoditi binaan Direktorat Jendral Perkebunan berdasarkan SK Menteri Pertanian No. 2599/Kpts/PD.310/10/2009 yang telah ditetapkan pada tanggal 19 Oktober 2009 adalah sebanyak 127 jenis. Menurut Dinas Perkebunan Jawa Barat ada sebanyak 30 jenis tanaman yang dapat tumbuh dengan baik di Jawa Barat. Tanaman tersebut terbagi menjadi 3 komoditas perkebunan, yaitu komoditas strategis ada 8 jenis tanaman, komoditas prospektif ada 12 jenis tanaman, dan komoditas unggulan spesifik lokal ada 10 jenis tanaman (Dinas Perkebunan Jawa Barat, 2018).

Masyarakat Jawa Barat telah memiliki pemahaman perkebunan dan agribisnis perkebunan sedari lama dan telah menjadi bagian dalam kehidupan mereka sehari-sehari, sehingga potensi perkebunan di Provinsi Jawa Barat cukup optimal. Untuk dapat lebih mengoptimalkan potensi perkebunan di Provinsi Jawa Barat, maka perlu dilakukan analisis kesesuaian lahan sumber daya perkebunan. Analisis kesesuaian lahan perkebunan sangat diperlukan di Provinsi Jawa Barat karena dengan adanya informasi kesesuaian lahan perkebunan ini, masyarakat Jawa Barat dapat lebih memaksimalkan lahan perkebunan mereka dengan baik.

Adanya perkembangan teknologi informasi saat ini memudahkan masyarakat dalam analisis kesesuaian lahan, salah satunya informasi berbasis Sistem Informasi Geografis (SIG). Oleh karena itu, dalam penelitian ini akan dibahas mengenai analisis kesesuaian lahan sumber daya perkebunan di Provinsi Jawa Barat dengan menggunakan teknologi SIG. Sebelumnya telah dilakukan penelitian yang sejenis di Provinsi Jawa Barat, yaitu oleh Suri (2015). Suri menganalisis potensi kesesuaian lahan sumber daya perkebunan untuk komoditas strategis di Provinsi Jawa Barat dengan metode pembobotan. Hasil dari penelitiannya adalah berupa sebaran potensi kesesuaian lahan untuk komoditas strategis. Yanti, dkk. (2015) juga melakukan penelitian yang sejenis, yaitu menganalisis kesesuaian lahan untuk tanaman perkebunan dengan menggunakan metode pembobotan. Hal yang serupa juga dilakukan oleh Faizah (2013) yang menganalisis potensi lahan kapas dengan metode pembobotan.

Mengadopsi dari Suri (2015), Yanti, dkk. (2015), dan Faizah (2013) penelitian ini menggunakan metode pembobotan. Tujuan dilakukan penelitian ini adalah untuk menganalisis dan mengevaluasi sebaran wilayah yang dapat dijadikan sebagai lahan sumber daya perkebunan untuk komoditas prospektif di Provinsi Jawa Barat. Batasan masalahnya meliputi analisis kesesuaian lahan sumber daya perkebunan komoditas prospektif dilakukan dengan menggunakan 6 parameter (temperatur, curah hujan, lereng, drainase tanah, tekstur tanah, dan jenis tanah); data temperatur diperoleh dari data kontur/ketinggian yang dihitung dengan pendekatan rumus Braak (1928, dalam Djaenudin, dkk., 2003); tahapan pembobotan (scoring) mengadopsi Rahadiati, dkk. (2010); analisis kesesuaian lahan yang 
dilakukan merupakan analisis kesesuaian lahan kualitatif; rekomendasi sebaran lokasi kesesuaian lahan perkebunan hanya dilakukan berdasarkan hasil analisis kesesuaian lahan yang sangat sesuai (S1); dan validasi data tutupan lahan tahun 2010 dilakukan dengan dukungan informasi citra dari google earth, terutama di daerah lahan perkebunan yang telah dianalisis sangat sesuai untuk lahan perkebunan komoditas prospektif.

\section{METODOLOGI}

Diagram alir dari metodologi penelitian yang dilakukan dapat dilihat pada Gambar 1. Metode scoring merupakan metode yang digunakan untuk analisis kesesuaian lahan, dimana setiap parameter kesesuaian lahan diperhitungkan dengan pembobotan yang berbeda. Parameter yang digunakan dalam analisis kesesuaian lahan meliputi peta temperatur (hasil konversi dari peta kontur/ketinggian), peta curah hujan, peta lereng, peta drainase tanah, peta tekstur tanah, dan peta jenis tanah.

Dalam menggunakan metode pembobotan (scoring), ada empat tahapan yang dilakukan, yaitu (Rahadiati, dkk., 2010):

1. Pembobotan Kesesuaian (Bob kes $_{\text {) }}$

Pembobotan kesesuaian dilakukan untuk membedakan nilai pada tingkat kesesuaian agar dapat diperhitungkan dalam perhitungan akhir zonasi. Pembobotan kesesuaian didefinisikan sebagai berikut:

a. S1 = sangat sesuai, bobot kesesuaian: 80

b. S2 = cukup sesuai, bobot kesesuaian: 60

c. S3 = sesuai bersyarat, bobot kesesuaian: 40

d. $\mathrm{N}$ = tidak sesuai, bobot kesesuaian: 1

Pemberikan bobot kesesuaian pada penelitian ini dilakukan berdasarkan kriteria kesesuaian lahan untuk masing-masing tanaman komoditas perkebunan yang terdapat dalam buku petunjuk teknis evaluasi lahan untuk komoditas pertanian oleh Djaenudin, dkk., (2003).

2. Pembobotan Parameter (Bob $\mathrm{bar}_{\text {) }}$

Setiap parameter dalam analisis kesesuaian lahan mempunyai peran yang berbeda-beda, artinya parameter yang paling berpengaruh akan mempunyai bobot yang lebih tinggi dibandingkan yang kurang berpengaruh. Jumlah total dari semua bobot parameter adalah 100. Pada penelitian ini, seluruh parameter yang digunakan dianggap mempunyai pengaruh yang sama, sehingga bobot setiap parameter pada penelitian ini adalah 100/6.

3. Pembobotan Scoring (Bob score $_{\text {) }}$

Pembobotan scoring dilakukan untuk menghitung tingkat kesesuaian berdasarkan bobot kesesuaian (Bobkes) dan bobot parameter (Bob $b_{p a r}$ ). Untuk parameter 1 sampai $n$, perhitungannya menggunakan Rumus 1.

$$
\text { Bob }_{\text {score }}=\frac{\left(\text { Bob }_{\text {kes }-1} * \text { Bob }_{\text {par }-1}\right)+\cdots+\left(\text { Bob }_{\text {kes }-n} * \text { Bob }_{\text {par }-n}\right)}{\text { Bob }_{\text {par }-1}+\text { Bob }_{\text {par }-n}}
$$

Keterangan :

$\begin{array}{ll}\text { Bob }_{\text {score }} & =\text { bobot scoring } \\ \text { Bob }_{\text {kes }} & =\text { bobot kesesuaian } \\ \text { Bob }_{p a r} & =\text { bobot parameter }\end{array}$

Reka Geomatika - 28 
4. Kesesuaian scoring (Kes score $_{\text {) }}$

Kesesuaian scoring ditetapkan berdasarkan nilai dari pembobotan scoring (Bob score$_{\text {, }}$, yaitu:

1) $S 1$ (sangat sesuai): apabila bobot scoring $\geq 80$

2) S2 (cukup sesuai): apabila bobot scoring antara 60 - 80

3) S3 (sesuai bersyarat): apabila bobot scoring antara $40-60$

4) N (tidak sesuai): apabila bobot scoring $<4$

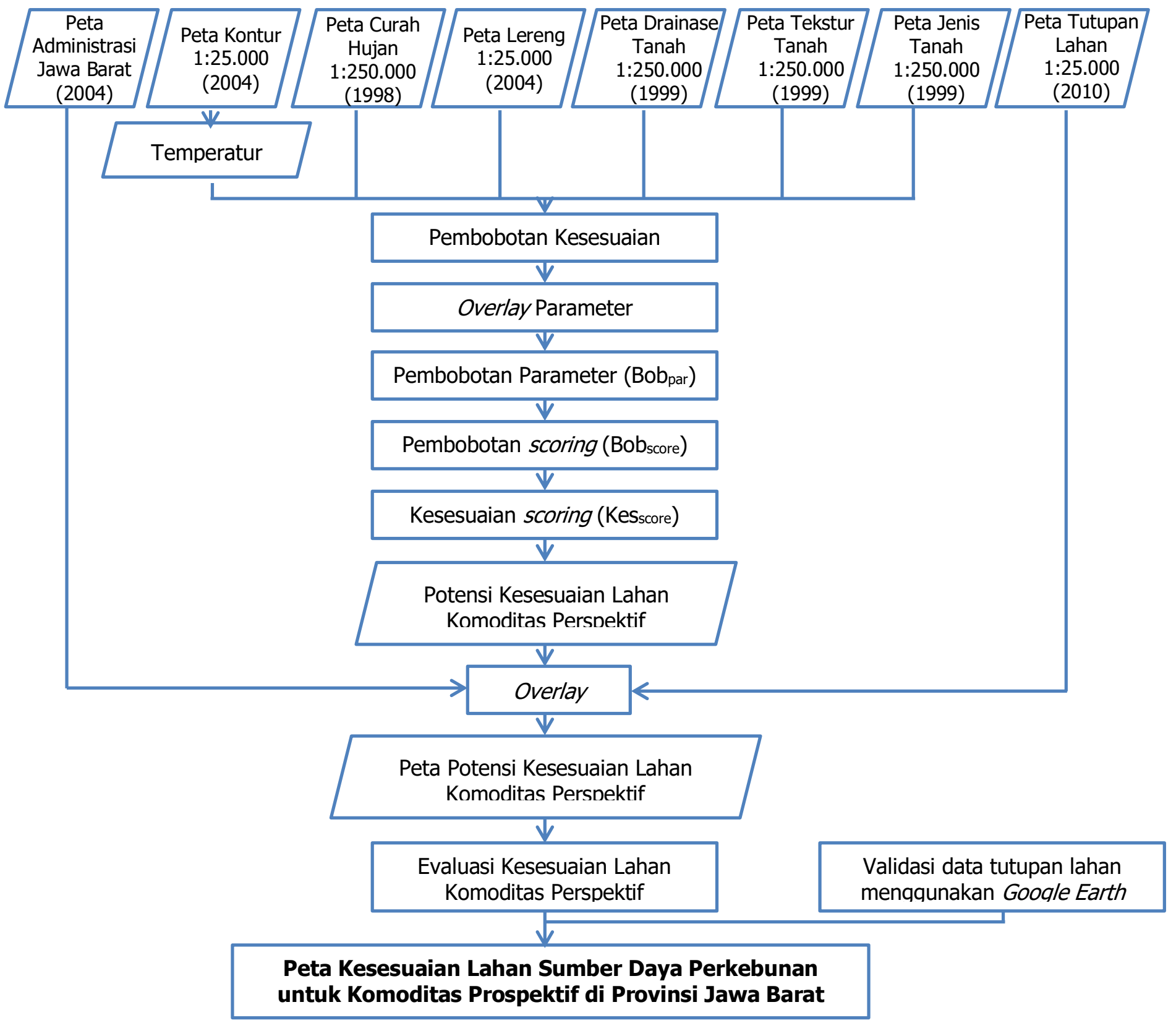

Gambar 1. Metodologi Penelitian

Berdasarkan hasil analisis potensi kesesuaian lahan yang diperoleh, tingkat potensi kesesuaian lahan sumber daya perkebunan komoditas prospektif di Provinsi Jawa Barat diklasifikasikan menjadi 4 (empat) kelas kesesuaian lahan, yaitu sangat sesuai (S1), cukup sesuai (S2), sesuai bersyarat (S3), dan tidak sesuai (N). Selanjutnya Peta Potensi Kesesuaian 
Lahan tersebut di-overlay-kan dengan Peta Tutupan Lahan dan Peta Batas Administrasi Provinsi Jawa Barat untuk mendapatkan sebaran lokasi kesesuaian lahan sumber daya perkebunan komoditas prospektif di Provinsi Jawa Barat.

\section{HASIL DAN PEMBAHASAN}

Hasil dari penelitian ini adalah peta potensi kesesuaian lahan sumber daya perkebunan komoditas prospektif di Provinsi Jawa Barat. Contoh hasil pemetaan kesesuaian lahan sumber daya perkebunan komoditas prospektif di Provinsi Jawa Barat dapat dilihat pada Gambar 2 dan Gambar 3.

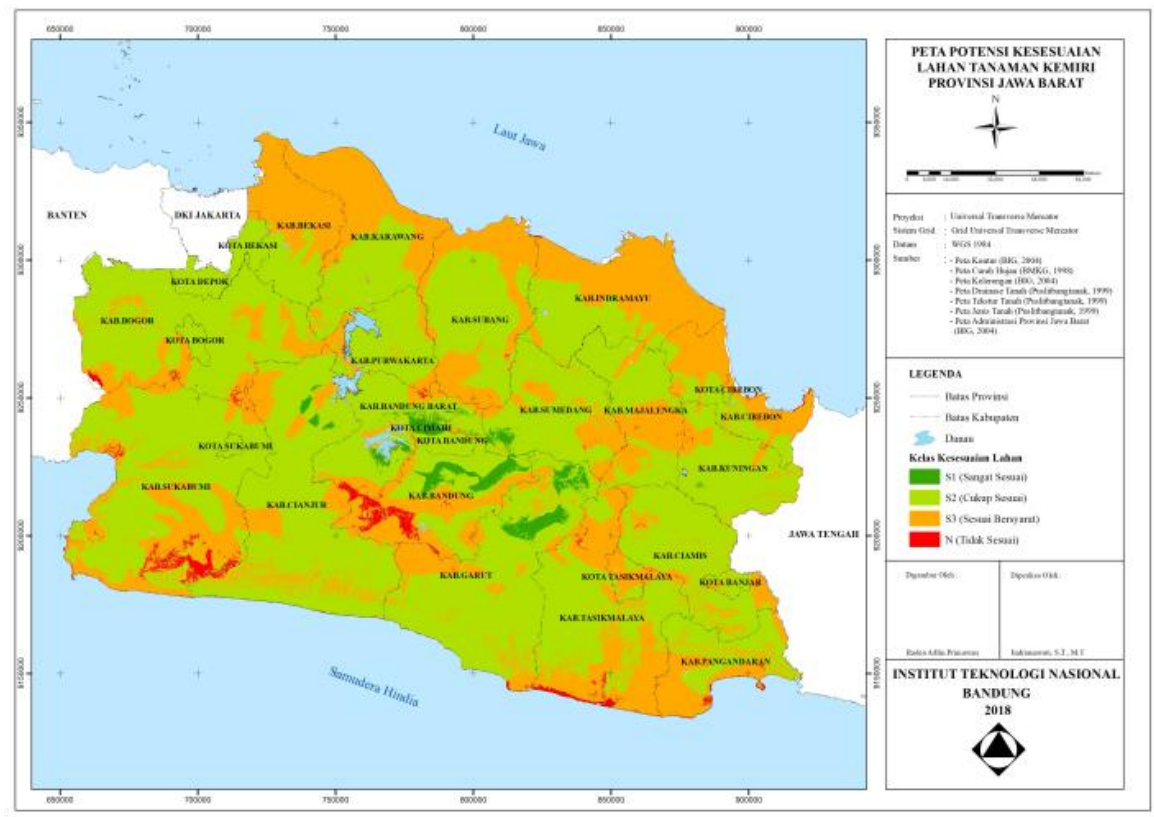

Gambar 2. Peta Potensi Kesesuaian Lahan Tanaman Kemiri di Provinsi Jawa Barat

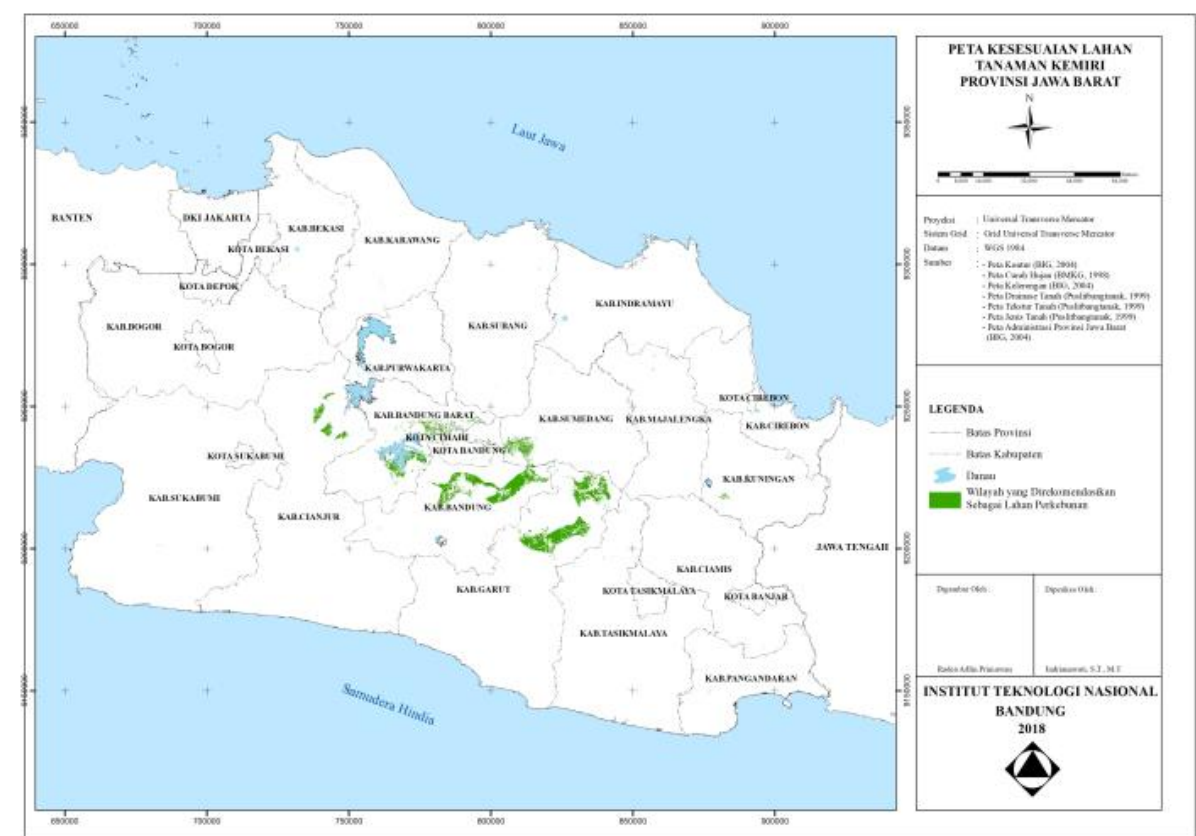

Gambar 3. Peta Kesesuaian Lahan Tanaman Kemiri di Provinsi Jawa Barat

Reka Geomatika - 30 


\subsection{Analisis Data}

Data yang digunakan pada penelitian meliputi peta administrasi (2004), peta kontur (2004), peta curah hujan (1998), peta lereng (2004), peta drainase tanah (1999), peta tekstur tanah (1999), peta jenis tanah (1999), dan peta tutupan lahan (2010). Jika ditinjau berdasarkan tahun pembuatan peta yang digunakan, data/peta yang digunakan untuk menganalisis potensi dan mengevaluasi kesesuaian lahan sumber daya perkebunan komoditas strategis di Provinsi Jawa Barat memiliki tahun pembuatan yang berbeda-beda dan bukan yang terbaru (update). Hal ini menyebabkan hasil analisis potensi kesesuaian lahan dalam penelitian ini bukan analasis kesesuaian lahan aktual, seperti yang diungkapkan oleh Djaenudin, dkk. (2003). Analisis potensi kesesuaian lahan sumber daya perkebunan yang aktual adalah kesesuaian lahan yang dilakukan dengan mengacu pada penggunaan lahan sekarang (present landuse).

\subsection{Analisis Potensi dan Evaluasi Kesesuaian Lahan Sumber Daya Perkebunan Komoditas Prospektif di Provinsi Jawa Barat}

Analisis kesesuaian lahan sumber daya perkebunan komoditas prospektif di Provinsi Jawa Barat ditentukan berdasarkan hasil evaluasi antara sebaran potensi kesesuaian lahan terhadap tutupan lahan. Berdasarkan data tutupan lahan pada tahun 2010, Jawa Barat memiliki 10 jenis tutupan lahan, yaitu hutan primer, hutan sekunder, kebun/perkebunan, ladang/tegalan, rawa, sawah, semak/belukar, tambak/empang, dan terbangun. Mengacu pada SNI 7645 tentang Klasifikasi Penutup Lahan, tidak semua tutupan lahan yang terdapat di Provinsi Jawa Barat dapat direkomendasikan sebagai lahan perkebunan, hanya terdapat 3 (tiga) jenis tutupan lahan yang sesuai untuk direkomendasikan sebagai lahan perkebunan, yaitu kebun/perkebunan, ladang/tegalan, dan sawah. Tutupan lahan yang tidak dapat direkomendasikan sebagai lahan perkebunan terdiri dari lahan hutan primer (merupakan hutan yang tumbuh berkembang dan masih belum mengalami investasi manusia); lahan hutan sekunder (merupakan hutan tumbuh berkembang dan sudah mengalami investasi manusia); rawa (merupakan lahan yang tergenang air payau atau tawar secara permanen); semak/belukar (merupakan kawasan lahan yang kering dan sudah ditumbuhi dengan vegetasi alami); sungai/danau/waduk (merupakan daerah perairan); tambak/empang (merupakan lahannya berfungsi untuk aktifitas perikanan); dan lahan terbangun (merupakan sudah mengalami substansi penutupan lahan).

Analisis lahan perkebunan yang masih dapat direkomendasikan untuk ditanami sumber daya perkebunan komoditas prospektif diperoleh dari evaluasi antara sebaran potensi kesesuaian lahan dengan tingkat S1 terhadap tutupan lahan. Hasil analisis potensi kesesuaian lahan sumber daya perkebunan komoditas prospektif di Provinsi Jawa Barat dapat dilihat pada Tabel 1.

Tabel 1. Analisis Potensi Kesesuaian Lahan Sumber Daya Perkebunan Komoditas Prospektif di Provinsi Jawa Barat

\begin{tabular}{clcrrr}
\hline \multirow{2}{*}{ No } & \multirow{2}{*}{ Tanaman } & \multicolumn{4}{c}{ Luas (ha) } \\
\cline { 3 - 6 } & S1 & S2 & \multicolumn{1}{c}{ S3 } & \multicolumn{1}{c}{$\mathbf{N}$} \\
\hline 1 & Aren & - & $1.084 .449,41$ & $2.564 .006,45$ & $63.121,12$ \\
\hline 2 & Kemiri sunan & $61.921,98$ & $2.953 .754,51$ & $653.537,31$ & $42.363,90$ \\
\hline 3 & Kelapa sawit & - & $1.301 .917,70$ & $2.207 .771,80$ & $201.886,77$ \\
\hline 4 & Kelapa hibrida & - & $1.681 .714,29$ & $1.957 .376,43$ & $72.487,00$ \\
\hline 5 & Pala & - & - & $1.565 .339,60$ & $2.146 .238,08$ \\
\hline 6 & Lada & $4.586,31$ & $1.632 .378,22$ & $2.045 .389,44$ & $29.223,74$ \\
\hline 7 & Nilam & - & - & $696.145,29$ & $3.015 .322,04$ \\
\hline 8 & Jambu mete & - & $128.227,05$ & $2.946 .656,90$ & $636.693,76$ \\
\hline 9 & Kayu manis & 353,12 & $1.342 .933,63$ & $2.238 .248,73$ & $130.042,23$ \\
\hline
\end{tabular}

Reka Geomatika - 31 
Tabel 1. Analisis Potensi Kesesuaian Lahan Sumber Daya Perkebunan Komoditas Prospektif di Provinsi Jawa Barat (Lanjutan)

\begin{tabular}{cccccc}
\hline \multirow{2}{*}{ No } & \multirow{2}{*}{ Tanaman } & \multicolumn{5}{c}{ Luas (ha) } \\
\cline { 3 - 6 } & Kemiri & S1 & S2 & S3 & N \\
\hline 10 & $61.921,98$ & $2.370 .490,92$ & $1.227 .379,43$ & $51.801,25$ \\
\hline 11 & Panili & $2.141,74$ & $2.634 .009,20$ & $1.057 .073,90$ & $18.352,87$ \\
\hline 12 & Jarak & - & $455.307,87$ & $3.230 .895,85$ & $25.374,01$ \\
\hline
\end{tabular}

Berdasarkan Tabel 1 dapat diketahui bahwa hanya terdapat 5 tanaman dari 12 tanaman yang mempunyai potensi kesesuaian lahan dengan tingkat klasifikasi S1 (sangat sesuai), yaitu kemiri sunan, lada, kayu manis, kemiri, dan panili. Mengacu pada hasil analisis potensi kesesuaian lahan dengan tingkat S1 yang dievaluasi terhadap tutupan lahan di Provinsi Jawa Barat, maka dapat diketahui sebaran wilayah yang masih dapat direkomendasikan sebagai lahan perkebunan. Sebaran wilayah di Provinsi Jawa Barat yang direkomendasikan sebagai lahan perkebunan dapat dilihat pada Tabel 2.

Tabel 2. Sebaran Wilayah yang Direkomendasikan Sebagai Lahan Perkebunan Komoditas Prospektif di Provinsi Jawa Barat

\begin{tabular}{|c|c|c|c|c|}
\hline No & Tanaman & Lokasi Lahan & Luas (ha) & Total (ha) \\
\hline \multirow[t]{10}{*}{1} & Kemiri Sunan & 1. Kab. Bandung & $12.986,21$ & $40.617,75$ \\
\hline & & 2. Kab. Bandung Barat & $4.944,67$ & \\
\hline & & 3. Kab. Cianjur & $2.791,47$ & \\
\hline & & 4. Kab. Garut & $15.944,29$ & \\
\hline & & 5. Kota Bandung & 167,57 & \\
\hline & & 6. Kota Cimahi & 434,92 & \\
\hline & & 7. Kab. Kuningan & 295,58 & \\
\hline & & 8. Kab. Purwakarta & 21,26 & \\
\hline & & 9. Kab. Sumedang & $3.029,50$ & \\
\hline & & 10. Kab. Tasikmalaya & 2,27 & \\
\hline \multirow[t]{4}{*}{2} & Lada & 1. Kab. Bandung & $1.065,16$ & $2.828,71$ \\
\hline & & 2. Kab. Bandung Barat & 43,39 & \\
\hline & & 3. Kab. Garut & $2.154,68$ & \\
\hline & & 4. Kab. Tasikmalaya & 8,69 & \\
\hline \multirow[t]{4}{*}{3} & Kayu Manis & 1. Kab. Bandung & 7,84 & 177,36 \\
\hline & & 2. Kab. Bandung Barat & 134,29 & \\
\hline & & 3. Kab. Garut & 34,36 & \\
\hline & & 4. Kab. Tasikmalaya & 0,87 & \\
\hline \multirow[t]{10}{*}{4} & Kemiri & 1. Kab. Bandung & $12.986,21$ & $40.617,75$ \\
\hline & & 2. Kab. Bandung Barat & $4.944,67$ & \\
\hline & & 3. Kab. Cianjur & $2.791,47$ & \\
\hline & & 4. Kab. Garut & $15.944,29$ & \\
\hline & & 5. Kota Bandung & 167,57 & \\
\hline & & 6. Kota Cimahi & 434,92 & \\
\hline & & 7. Kab. Kuningan & 295,58 & \\
\hline & & 8. Kab. Purwakarta & 21,26 & \\
\hline & & 9. Kab. Sumedang & $3.029,50$ & \\
\hline & & 10. Kab. Tasikmalaya & 2,27 & \\
\hline \multirow[t]{5}{*}{5} & Panili & 1. Kab. Bandung & 123,41 & 674,21 \\
\hline & & 2. Kab. Bandung Barat & 388,84 & \\
\hline & & 3. Kab. Garut & 9,28 & \\
\hline & & 4. Kota Bandung & 96,31 & \\
\hline & & 5. Kota Cimahi & 54,94 & \\
\hline
\end{tabular}


Berdasarkan Tabel 2 dapat diketahui luas lahan di Provinsi Jawa Barat yang masih dapat ditanami kemiri sunan adalah sebesar $40.617,75$ ha yang tersebar di 10 kabupaten/kota, lada seluas 2.828,71 ha yang tersebar di 4 kabupaten/kota, kayu manis seluas 177,36 ha yang tersebar di 4 kabupaten/kota, kemiri seluas $40.617,75$ ha yang tersebar di 10 kabupaten/kota, dan panili seluas 674,21 ha yang tersebar di 5 kabupaten/kota. Setelah dilakukan validasi terhadap tutupan lahan terbaru (interpretasi citra dengan google earth), dapat diketahui bahwa luas lahan perkebunan yang direkomendasikan untuk setiap jenis tanaman tersebut secara kualitatif mengalami penurunan luas lahan.

\section{KESIMPULAN}

Berdasarkan hasil penelitian dan uraian pembahasan telah dilakukan, maka dapat diambil kesimpulan sebagai berikut:

1. Sumber daya perkebunan komoditas prospektif yang masih dapat direkomendasikan lahannya di Provinsi Jawa Barat hanya ada 5 (lima) tanaman dari 12 (dua belas) jenis tanaman, meliputi kemiri sunan dengan luas lahan sebesar $40.617,75$ ha yang tersebar di 10 kabupaten/kota; lada dengan luas lahan sebesar 2.828,71 ha yang tersebar di 4 kabupaten/kota; kayu manis dengan luas lahan sebesar 177,36 ha yang tersebar di 4 kabupaten/kota; kemiri dengan luas lahan sebesar $40.617,75$ ha yang tersebar di 10 kabupaten/kota; dan panili dengan luas lahan sebesar 674,21 ha yang tersebar di 5 kabupaten/kota.

2. Setelah dilakukan validasi terhadap tutupan lahan terbaru (interpretasi citra dengan google earth), luas lahan perkebunan yang direkomendasikan untuk setiap jenis tanaman tersebut secara kualitatif mengalami penurunan luas lahan. Penurunan luas lahan terjadi karena adanya alih fungsi lahan yang sebelumnya berupa sawah, ladang/tegalan, dan perkebunan berubah menjadi lahan terbangun.

\section{DAFTAR PUSTAKA}

BPS [Badan Pusat Statistik] Provinsi Jawa Barat. (2017). Provinsi Jawa Barat Dalam Angka 2017. Kota Bandung.

Dinas Perkebunan Provinsi Jawa Barat. (2018). Sejarah Dinas Perkebunan Provinsi Jawa Barat. Dipetik 20 Maret 2018 dari http://disbun.jabarprov.go.id/index.php/pages/sejarah_ disbun.

Djaenudin, D., Marwan H., Subagjo H., dan A. Hidayat. (2003). Petunjuk Teknis Evaluasi Lahan Untuk Komoditas Pertanian. Balai Penelitian Tanah, Puslitbangtanak, Badan Penelitian dan Pengembangan Pertanian. Bogor.

Faizah. (2013). Pengembangan Potensi Lahan Kapas di Kabupaten Lamongan Menggunakan GIS. Jurnal Agromix Vol.3 No.1 Tahun 2013 hal. 14-21. Fakultas Pertanian Universitas Yudharta Pasuruan. Dipetik 19 Maret 2018 dari http://jurnal.yudharta.ac.id/v2/index.php/ AGROMIX/article/view/774/630.

Rahadiati, A., Suzan, N.G., Dewayany, S. (2010). Kajian Potensi Sumber Daya Pesisir Kabupaten Rokan Hilir. Pusat Survei Sumber Daya Alam Laut - Bakorsultanal, Cibinong.

SK Menteri Pertanian No. 2599/Kpts/PD.310/10/2009.

SNI 7645 tentang Klasifikasi Penutup Lahan.

Suri, D.P.R. (2015). Pemetaan Potensi Sumber Daya Perkebunan Untuk Komoditas Strategis di Provinsi Jawa Barat. Laporan Skripsi Jurusan Teknik Geodesi, FTSP, Itenas. Bandung.

Undang-Undang Republik Indonesia Nomor 18 Tahun 2004 tentang Perkebunan. 
Yanti, D., Arlius, F., dan Nurmansyah, W. (2015). Analisis Kesesuaian Lahan untuk Tanaman Perkebunan di Kecamatan Bungus Teluk Kabung Kota Padang. Jurnal Teknologi Pertanian Andalas Vol.19 No.1 Maret 2015, ISSN 1410-1920, hal 15-26. Fakultas Teknologi Pertanian, Universitas Andalas. Padang. Dipetik 19 Maret 2018 dari http://tpa.fateta. unand.ac.id/index.php/JTPA/article/view/8/14. 